\section{CAMPONESES E ESQUECIMENTO NA ANTIGUIDADE TARDIA: AS REVOLTAS DOS BAGAUDAS E DOS CIRCUNCELIÕES}

Uiran Gebara da Silva* * Pesquisador em pós-doutoramento em História Social, RESUMO: Esse artigo apresenta alguns dos problemas com os quais eu tive de lidar ao realizar um estudo comparativo entre dois conjuntos de revoltas rurais do Império Romano tardio: as revoltas dos bagaudas na Gália e dos circunceliões na África. O artigo toma como eixo articulador a hipótese lançada por E. A. Thompson sobre o papel do esquecimento na produção dos relatos antigos sobre os bagaudas e a problematiza. Num segundo momento o artigo trata do problema relacionado à compreensão do caráter social de ambos os grupos, levando em consideração os múltiplos relatos presentes nas fontes antigas e as divergentes interpretações modernas sobre eles, enfatizando a necessidade de se reconhecer a tópica da inversão social como um elemento que diferencia os relatos sobre os revoltosos daqueles sobre a bandidagem. Outro elemento importante é o reconhecimento da heterogeneidade dos discursos cristãos com relação às classes subalternas e aos revoltosos, que apontam não para um fortalecimento do patronato rural, mas para o enfraquecimento ou para a crise dessas relações no campo tardo-romano.

PALAVRAS-CHAVE: revoltas; camponeses; heresia; história das classes subalternas; Antiguidade Tardia.

PEASANTS AND FORGETFULNESS IN LATE ANTIQUITY: THE REBELLIONS OF THE BAGAUDAE AND THE CIRCUMCELLIONS
Universidade de São Paulo. Bolsista Fapesp. Membro do Laboratório de Estudos sobre o Império Romano Mediterrâneo Antigo (LEIR-MA).

\begin{abstract}
This article presents some questions with which I had to deal when I did a comparative study between two sets of rural revolts of the late Roman Empire: the revolts of Bacaudae in Gaul and Circumcellions in Africa. It takes as its central theme the problematizing of E. A. Thompson's hypothesis concerning the role of the forgetfulness in the production of the ancient accounts of the Bacaudae. Secondly, the article deals with the problem regarding the comprehension of both groups' social characteristics, taking into account their varied reports in the ancient sources as well as their different modern interpretations, emphasizing the need to recognize the topic of social inversion as an element that differentiates the accounts of the rioters from those on banditry. Another
\end{abstract}


important element is the recognition of the diversity of Christian discourse regarding subaltern classes and the peasant rebels, which expresses not the strengthening of rural patronage, but its weakening, or the crisis of those relations in the Later Roman countryside.

KEYWORDS: rebellions; peasants; heresy; history of the subaltern classes; Late Antiquity.

\section{INTRODUÇÃO: AS REVOLTAS E O ESQUECIMENTO}

E sse artigo apresenta alguns dos problemas com os quais eu tive de lidar ao realizar um estudo comparativo entre dois conjuntos de revoltas rurais do Império Romano tardio: as revoltas dos bagaudas e dos circunceliões. As insurgências rurais praticadas por esses dois grupos de habitantes das zonas rurais da Gália e da África, respectivamente, ocorreram entre o século III e V d.C. Um dos objetivos da pesquisa, passo necessário para a comparação, era compreender e descrever o caráter social de ambos os grupos, levando em consideração os múltiplos relatos presentes nas fontes antigas e as divergentes interpretações modernas sobre eles, cuja abrangência vai desde multidões rurais sob comando patronal, passando por rebeliões camponesas até movimentos de extremismo religioso fanático.

Em meio à tamanha falta de consenso, uma caracterização preliminar desses dois grupos era necessária. Assim, no que diz respeito aos bagaudas, é possível dizer que este é o nome dado a grupos de habitantes insurretos nas regiões rurais na Gália tardo-romana que teriam atuado no século III e no século V d.C. (embora alguns autores acreditem que tenham agido também no século IV). A localização espacial dos bagaudas é um tanto vaga na maior parte da documentação, sendo um pouco mais precisa nos textos relativos a meados do século $\mathrm{V}$ que localizavam as revoltas mais precisamente no noroeste, na região da Armórica. Já os circunceliões são um movimento insurgente também rural, mas da África romana, cuja maior parte das fontes documentais associa à Numídia tardo-romana, que foram sistematicamente mencionados nos textos de Agostinho escritos contra os donatistas. Há, imediatamente, uma grande diferença entre os bagaudas e os circunceliões, que é a classificação dos últimos como uma heresia cristã, o que, por sua vez, fez com que a maior parte dos estudiosos do final do século XX visse os circunceliões especificamente como uma ordem ascética e violenta de origem rural.

A interpretação de E. A. Thompson sobre os bagaudas foi central para o desenvolvimento dessa pesquisa, pois foi decisiva para a reflexão sobre como problematizar o processo pelo qual a documentação sobre as revoltas fora criada por autores antigos. Em um importante artigo, ao discutir a escassez documental sobre o fenômeno dos bagaudas, Thompson (1952) acusou os produtores de registros escritos antigos de evitar falar abertamente sobre as revoltas dos bagaudas. Isto é, para Thompson, elites na Gália teriam criado uma representação histórica das ações dos revoltosos rurais marcada pelo esforço do esquecimento da ação desses grupos subalternos. Dessa forma, Thompson teria formulado essa problemática que eu acredito valer não só para entender os bagaudas, mas também as ações dos circunceliões. 
A sugestão de Thompson de que teria havido um silêncio intencional das fontes sugere um problema teórico e metodológico que é o centro da investigação dessas revoltas e, por isso, estabeleci essa problemática como o núcleo organizador da pesquisa. Nesse sentido, em lugar de simplesmente aceitar a proposta de Thompson, busquei colocá-la em questão e refletir sobre a problemática do esquecimento, inclusive testando seus limites. Nesse sentido, foi necessário questionar a efetividade desse silêncio (e até mesmo sua real existência), as formas com as quais tal silêncio pôde e pode ser produzido, e, finalmente, os fatores que o motivam: o conflito social, a rigidez dos modelos literários, ou uma articulação das duas coisas. No que diz respeito às motivações dos autores e das fontes antigos, investigar a história das classes subalternas é ter de lidar com o esquecimento gerado pelos produtores de vestígios textuais, um esquecimento que não é pura intenção política e também não é uma ação puramente individual dos autores. Ele é parte integrante da tradição e das práticas de escrita que se atualizam na ação de um escritor. Ele é ideologia produzida coletivamente. Assim, também entendo a ação dos modelos literários como forma de produção, pela classe dominante, do esquecimento da ação das classes subalternas. Porém, no que diz respeito à efetividade desse esquecimento, não me parece que ele seja tão homogêneo como Thompson dava a entender. Diferentes autores, diferentes estruturas formais literárias, diferentes contextos políticos e diferentes usos retóricos permitiram menções diferenciadas dos dois movimentos insurgentes nas suas várias manifestações textuais. Investigar essa história é um pouco menos uma busca por uma história secreta, lida apenas nas metáforas e alegorias, ou por aquilo que ocorreu, mas que foi escondido, e é um pouco mais uma investigação da documentação que muitas vezes insinua e algumas vezes apresenta claramente para o olhar atento as trajetórias possíveis da história desses grupos, abortadas, contudo, pela força e pela violência das elites. Da mesma forma, outras vezes, é a mudança da perspectiva que descobre a ação das classes subalternas em eventos antes só vistos como obra das elites.

\section{Comparando revoltas}

Nesse contexto, a própria condição de produção de um estudo comparado também exige uma breve apresentação de suas dificuldades e suas relações com a problemática da história de classes subalternas. Uma investigação comparativa dos dois grupos insurgentes poderia ser feita dentro do quadro de referência de uma História do Império Romano. Isso inscreveria a investigação em uma problemática mais geral que derivaria de questões ligadas à existência ou não de uma sociedade romana ao redor do Mediterrâneo. No entanto, o processo de especialização que a pesquisa científica impõe no século XXI demanda que se olhe para cada um dos dois grupos com um enfoque de história regional ou local. Isso cria uma polarização do processo de investigação que gera impasses. Em ambos os casos essa polarização é produzida pelos pressupostos não ditos. No primeiro caso, pressupõe-se que a conexão entre os dois grupos esteja na existência de um Império e que sua História leve a reboque as histórias locais, meros efeitos de um motor central ou do Império como uma fraca força política ligando sociedades locais centrífugas. No outro caso, pressupõe-se que os 
eventos locais tenham uma história particular e que a sua relação com outras comunidades seja acidental. Os próprios efeitos do Império seriam acidentais. Ainda, geralmente a organização do conjunto de documentos escritos ou materiais acaba sendo formulada de acordo com a projeção no passado de divisões nacionais modernas, o que limita seriamente a investigação de pontos de contato ou de áreas de intersecção. A perspectiva integrada, nesse caso, fica severamente limitada. Nenhuma das duas alternativas é satisfatória isoladamente, e em ambas o pesquisador encontra inúmeras dificuldades para tratar da problemática do esquecimento das ações das classes subalternas.

O esforço em tentar escapar dessa polarização significou evitar um enquadramento generalizante do estudo e, simultaneamente, não produzir uma investigação sobre duas histórias separadas que se relacionam superficialmente. Para conseguir isso, tentei articular três dimensões passíveis de comparação que me permitissem problematizar, estabelecer pontos de contatos e examinar conjuntamente bagaudas e circunceliões.

Essas dimensões comparativas seriam a relação desses grupos com as estruturas imperiais, a condição camponesa ou de trabalhadores rurais e, por último, as estruturas literárias que dão forma à documentação. Isto é, orientaram a minha investigação da documentação as seguintes preocupações: em primeiro lugar, de que maneira a existência e as ações desses movimentos de insurgência se relacionavam com a presença das estruturas imperiais na Gália e na África; em segundo, a busca pelas similaridades e diferenças entre as relações de trabalho rural nas duas regiões; e, em terceiro lugar, uma compreensão das tradições de composição e recepção dos textos através das quais bagaudas e circunceliões objetivaram-se na memória social de seu tempo. Esse olhar comparativo me permitiu ao longo da investigação estabelecer algumas impressões com respeito à caracterização social dos dois grupos insurretos.

\section{A CARACTERIZaÇão dos REBEldes E A TÓPICA dA INVERSÃo SOCIAL}

Para Thompson, os bagaudas deveriam ser compreendidos em termos de um processo de desenvolvimento que vai dos bandidos Maternus e Bulla Felix no século II d.C. até suas várias manifestações no $\mathrm{V}$ e, ao mesmo tempo, expresso em uma documentação na qual os escritores compartilhariam uma má vontade em escrever ou apresentar o enfrentamento, pelos generais romanos, de adversários tão pouco dignificantes: uma produção voluntária de esquecimento, cujas menções mais claras à revolta camponesa na Gália estariam associadas às duas grandes crises do Império Romano e do domínio sobre o campesinato. A crítica contra Thompson nas décadas recentes usou de duas estratégias para se contrapor às suas ideias sobre bagaudas. A primeira é a de desacreditar a documentação. A segunda é a de afirmar a vagueza de sentido do termo bagaudas. No primeiro caso, ignora-se a comédia anônima Querolus por sua difícil datação, e recusa-se o uso do De Redito Suo de Rutílio Namaciano por causa da história complicada de seus manuscritos (Bartholomew, 1982; Minor, 1996). E na segunda estratégia, busca-se demonstrar as divergências entre o uso do termo referentes às ocorrências no século III (em Eutrópio, Aurélio Vitor, Jerônimo e Optato) com os usos do 
século V (Vita germani, Sidônio Apolinário, Salviano, Hidácio, Optato, uma crônica anônima de 452 e Jordanes), argumentando-se em favor de uma suposta proximidade semântica de bagaudas com a bandidagem e, em seguida, assimilando a menção de qualquer líder associado aos bagaudas à figura de um potentado local. A visão de um longo processo também está presente nos críticos de Thompson. Estes acentuaram ainda mais as características associadas ao banditismo do século II, distanciando as revoltas dos problemas dos camponeses do século III e V, e, ao mesmo passo, descartaram a ideia de uma conspiração do esquecimento das ações das classes subalternas, preferindo ler ali menções veladas aos patronos locais.

Enquanto isso, no que diz respeito às interpretações dos circunceliões, um processo metodológico quase inverso acontece: a visão predominante ao final do século XX buscou circunscrever precisamente o significado do termo circuncelião. E, nesse contexto, a partir de um conjunto documental profundamente polissêmico, ambíguo e contraditório, a maior parte dos estudiosos caracterizou os circunceliões estritamente como monges ascetas e violentamente obcecados com o martírio. A partir dessa classificação restrita, os estudos mais recentes defenderam que os objetivos sociais de suas ações, que aparecem explicitamente na documentação, deveriam merecer bem menos atenção do que a ideologia religiosa expressa pelos revoltosos. ${ }^{2}$

A tentativa de aproximar semanticamente o termo bagaudas (bacaudae ou bagaudae) daqueles utilizados para se referir ao banditismo (latrones) era o que permitia uma leitura das ações desses grupos como instrumento da ação de agentes locais mais poderosos. Na base dessa tentativa estava a ideia de que o termo bagaudas teria passado por um processo de abstração e perdido seu sentido original do século III: para alguns autores, sendo totalmente assimilado ao campo do banditismo; para outros, esvaziando-se completamente de significado ou podendo querer dizer qualquer insurgência. A assimilação de bagaudas a bandidos, dado que o termo latro é sistematicamente utilizado como um insulto político, sempre com o intuito de colocar um adversário na ilegalidade, permite, por sua vez, a assimilação de bandidos a poderosos insurgentes ou a candidatos a usurpadores. Esse jogo de assimilações, utilizado como ferramenta de análise do contexto social das crises na Gália romana dos séculos III e V, subordina toda possível agência camponesa à iniciativa de potentados ou, em algumas interpretações, até mesmo à dos bárbaros. ${ }^{3}$

Embora essa seja uma visão muito sedutora por sua flexibilidade, não é muito sustentável pela documentação. As primeiras menções aos bagaudas, dentro do contexto da crise política do século III, os colocam no imediato início do governo de Diocleciano,

\footnotetext{
${ }^{1}$ Proposta delineada para os bagaudas por Raymond Van Dam (1985) e sugerida para os circunceliões por C.R. Whittaker (1993 [1980]; 1995).

${ }^{2}$ Cf. Caner (2002) e Figuinha (2009). Um exemplo extremo disso é o artigo de Bruno Pottier (2008). Zeev Rubin combina as duas abordagens, seguindo Van Dam na interpretação dos bagaudas e vendo os circunceliões como ordens ascetas errantes (Rubin, 1995).

${ }^{3}$ Há alguns autores que interpretam as menções aos bagaudas como uma alegoria feita por autores pagãos para se referir a cristãos, ou mesmo a movimentos monásticos, o que se aproxima bastante da leitura restrita dos circunceliões, cf. Sanz Bonel, et al. (1995); Sanz Bonel (2000).
} 
pouco tempo depois de debelado um governo considerado usurpador na Gália. ${ }^{4}$ Os bagaudas só voltam a ser mencionados no contexto da presença bárbara na Gália do século V, ${ }^{5}$ e o momento no qual aparecem também é seguido por um novo governo usurpador na Gália. No entanto, dizer que perderam o sentido específico é ignorar que, com exceção dos textos mais poéticos, como Querolus e De Redito Suo, sempre está presente a caracterização dos bagaudas como algum tipo de trabalhador rural de baixo estatuto. E, por outro lado, nenhum autor antigo estabelece qualquer relação entre os bagaudas e os governos considerados ilegítimos. Apenas historiadores modernos enxergaram essa relação.

Ademais, há de fato um processo de abstração do termo bagaudas, mas esse processo não levou o termo a ser sinônimo de latrones, nem a perder todo o significado preciso. O processo de abstração fez com que o termo fosse usado cada vez mais com o sentido preciso de revoltas de trabalhadores rurais, quase a formulação de uma categoria sociológica. A chave para entender isso está em observar na documentação não apenas a presença de termos correlatos ao banditismo, mas também a presença de uma tópica que os textos sobre bagaudas (e também sobre os circunceliões) compartilham com a tradição literária saturnálica, com as comédias latinas e com os relatos de revoltas de escravos. ${ }^{6} \mathrm{Uma}$ tópica composta por três elementos: a ideia de inversão social, a ideia de idade de ouro igualitária e a inversão da autoridade (o único que verdadeiramente se encontra associado a relatos de banditismo). Essa tópica é muito forte nos textos mais substanciosos sobre os bagaudas (mesmo que se desconsidere Querolus e o De Redito Suo, onde ela é fundamental).

\section{a. Salviano de marselha e os bagaudas}

Um dos textos nos quais essa tópica não está claramente presente é De Gubernatione Dei de Salviano de Marselha. Mas a menção aos bagaudas que faz Salviano pode até ser caracterizada como favorável, uma vez que ele justifica as ações dos bagaudas como uma resposta à ação dos próprios agentes da ordem romana, os cobradores de impostos que os espoliaram e os grandes proprietários que tomaram indevidamente suas terras. Estes os prejudicaram de tal forma que forçaram romanos pobres a deixarem de ser romanos. O discurso de Salviano usualmente é classificado por historiadores como retoricamente carregado e exagerado, ao qual não se deve dar muita credibilidade (curiosamente, os mesmos historiadores raramente usam os mesmos critérios para analisar as palavras também enviesadas de Agostinho):

\footnotetext{
${ }^{4}$ Eutrópio, Breviarium, IX, 20 e Aurelius Victor, Liber de Cesaribus, XXXIX, 17.

${ }^{5}$ Salviano de Marselha, De Gubernatione Dei, 5.21-26, cf. 26-37; Orosio, Historia Adversus Paganus, VIII.25.2; 41.7; Hydatius, Chronica, 125, 128, 141, 142, 154; Chronica Gallica de 452: Chronica Minora, Monumentae Germanicae, 117-133; Constantius, Vita S. Germani, 28.40; Merobaudes, Panegyricus, 2.8-22; Inscrição sobre Merobaudes - CIL vi. 1724; Sidonio Apolinario, Carmina v 210-3; vii 246-8.

${ }^{6}$ Para um estudo geral da presença de inversões sociais nas práticas de culto e nos mitos romanos, cf. Versnell (1994).
} 
Meu discurso será agora sobre os bagaudas, que espoliados, oprimidos e feridos por juízes maus e cruéis, depois de terem perdido seus direitos romanos, ainda perderam a honra do nome romano. E esta sua infelicidade é imputada; imputamos este nome a partir de sua calamidade, imputamos um nome que nós mesmos fizemos! Chamamos de rebeldes, chamamos de perdidos aqueles que compelimos a serem criminosos. E de que coisas são feitos os bagaudas, senão das nossas iniquidades, senão das improbidades de juízes, senão daqueles que, por meio de confiscos e rapinas, transformaram em ganhos próprios o título de arrecadação pública e dos recolhimentos tributários fizeram sua presa - que em semelhança a animais selvagens não governam os que a eles se entregam, mas os devoram, que se apascentam não só do espólio de tantos homens, como costumam muitos ladrões, mas até mesmo de sua carne e, como se diz, de seu sangue? E assim é que homens oprimidos e golpeados, por meio do latrocínio de juízes, começam a se tornar quase bárbaros, já que não lhes era mais permitido ser romanos. Pois consentiram em ser o que não eram, já que não lhes era permitido ser o que foram, são obrigados a pelo menos defender a vida, uma vez que viram que sua liberdade fora completamente perdida. Ora, o que de diferente ainda agora acontece do que aconteceu então? Isto é, os que agora não são bagaudas não são a isso coagidos? Quão grande é o alcance da violência e das injúrias, que os impele a querer ser bagaudas, embora a sua fraqueza os impeça de o ser?! Assim são como cativos sob jugo de inimigos: toleram por necessidade o suplício, não por desejo; na alma desejam a liberdade mas aguentam a servidão suprema (Salviano de Marselha, De Gubernatione Dei, 5.6). ${ }^{7}$

\footnotetext{
${ }^{7}$ De Bacaudis nunc mihi sermo est, qui per malos judices et cruentos spoliati, afflicti, necati, postquam ius Romanae libertatis amiserant, etiam honorem Romani nominis perdiderunt. Et imputatur his infelicitas sua, imputamus his nomen calamitatis suae, imputamus nomen quod ipsi fecimus. Vocamus rebelles, vocamus perditos, quos esse compelimus criminosos. Quibus enim aliis rebus Bacaudae facti sunt, nisi iniquitatibus nostris, nisi improbitatibus iudicum, nisi eorum proscriptionibus et rapinis qui exactionis publicae nomen in quaestus proprii emolumenta verterunt et indictiones tributarias praedas suas esse fecerunt, qui in similitudinem immanium bestiarum non rexerunt traditos sibi, sed devorarunt, nec spoliis tantum hominum, ut plerique latrones solent, sed laceratione etiam et, ut ita dicam, sanguinem pascebantus. Ac sic actum est ut latrociniis iudicum strangulati homines et necati, inciperent esse quasi barbari, quia non permittebantur esse Romani. Acquieuerunt enim esse quod non erant, quia non permittebantur esse quod fuerant, coactique sunt vitam saltem defendere, quia se iam libertatem videbant penitus perdidisse. Aut quid aliud etiam nunc agitur quam tunc actum est, id est, ut qui adhuc Bacaudae non sunt, esse cogantur? Quantum enim ad uim atque iniurias pertinet, compelluntur ut velint esse, sed imbecillitate impediuntur ut non sint. Sic sunt ergo quasi captiui iugo hostium pressi: tolerant supplicium necessitate, non uoto; animo desiderant libertatem sed summam sustinent servitutem. (Todas as traduções do latim neste artigo foram feitas pelo autor).
} 
Essa retórica carregada de Salviano não deve ser ignorada, nem usada como justificativa para que se descarte o autor. O discurso de Salviano é rigorista, tanto por causa de sua responsabilização do cristão individual com relação aos pecados, quanto em sua crítica ao mau uso das relações de patronato. E é dentro desse campo de crítica dos pecados dos ricos e poderosos romanos cristãos que atua sua defesa dos bagaudas. Por causa de seu discurso rigorista, Salviano é um dos pontos mais importantes de comparação dos bagaudas com circunceliões.

\section{B. Optatus de Milevis E OS CiRCunCEliões}

Aquela mesma tópica (inversão social, inversão de autoridade, idade de ouro igualitária) pode ser associada aos circunceliões, ${ }^{8}$ mas ela também tem sido sistematicamente ignorada nesse outro conjunto documental. ${ }^{?}$

Contudo, essa tópica deve ser observada levando-se em consideração as diferenças que o estudo dos circunceliões como um movimento social insurgente apresenta, principalmente por causa das relações desses com o Donatismo. Em poucas palavras, o Donatismo, ao longo do século IV, foi o nome dado a um grupo de bispos cristãos africanos que se separou do outro grupo de bispos por causa de divergências com respeito à organização da Igreja cristã, à nomeação de bispos e ao que os bispos africanos fizeram durante as perseguições aos cristãos no tempo de Diocleciano. Durante a perseguição, muitos bispos teriam anatematizado e entregado as escrituras para serem queimadas. Outros, tentando mitigar o conflito e diminuir o número de mortos, agiram como agentes de controle dos próprios cristãos africanos, com muitos dos padres e leigos dispostos a se oferecer ao martírio. O Donatismo surgiu da recusa de parte dos cristãos e bispos africanos em reconhecer esses bispos que anatematizaram ou que auxiliaram no controle interno, que passaram a considerar como lapsi. Ao longo do século IV os donatistas e a dita ortodoxia católica, os cecilianistas, ${ }^{10}$ se organizaram quase como duas igrejas diferentes, cujo único elo comum era a Igreja cristã fora da África. ${ }^{11}$ Em meio a todas as divergências e confrontos,

\footnotetext{
${ }^{8}$ Optatus de Milevis, Contra donatistas, III.4; Agostinho, Epistolas, 23.6-7; 29.12; 35.2; 43.24; 51.3; 53.6; 76.3; 76.2; 81.1-7; 86; 87.4-8; 87.8-12; 88.10; 93.17; 100; 100.2; 105.1-7; 105.3-4; 106; 107; 108. 5, 14, 16, 18; 111.1; 131.1; 134.2; 139.1-2; 185; 185.8, 12, 15, 25-27, 30, 40; 204.1-5; 209.2; Contra Parm., I, 11.18; II 3.6; 9.19; Contra Gaudent., I 6.7; 22.25; 27.30; 28.32; 31.37; 36; 46; Contra Crescon., III 42.46; 43.47; IV 51.61; Brevis Colationis, III 11.21, 22; Contra Lit. Petil, I 24.26; II 23.53-55; 28.65; 37.88; 39.94; 52.120; 83.184; 88.195; 92.209; 103.237; Gesta cum Emerito, IX; IX 12; Gesta Collatio Carth., I 139; 188; 187-189; 197; 201; Ad Don. Post Collatio., 17.22; Enar. In Psalm., 54.26; 132.3, 4, 6; Possidio, Vida de Agostinho, cap. 9-15.

${ }^{9}$ Uma das poucas análises que a levam em conta é a de Neal Wood (1986).

${ }^{10}$ Seguindo o trabalho de Maureen Tilley (1997), prefiro chamar de cecilianistas o grupo que a maior parte da historiografia chama de "católicos". O propósito é usar com Ceciliano, o bispo defensor dos lapsi, o mesmo critério utilizado com Donato e evitar reproduzir na análise as distorções no debate donatista causadas pela retórica de Agostinho.

${ }^{11}$ Para uma das principais obras de síntese da questão donatista, cf. Frend (1951).
} 
o Donatismo permaneceu sendo classificado pelo centro imperial durante todo o século IV como um cisma e só passou a ser considerado uma heresia no começo do século V. Em grande medida isso foi resultado dos esforços de Agostinho, que conseguiu associar, perante os olhos imperiais, os donatistas aos circunceliões. Várias interpretações já foram formuladas para entender o cisma: a oposição entre martírio e disciplina eclesiástica, a recusa da predominância do bispado de Roma sobre o de Cartago, a interpretação mais concreta do evangelho da religiosidade donatista ou a recusa da subordinação da Igreja ao Império.

Os circunceliões sempre são mencionados pelos cecilianistas em meio às disputas pela legítima Igreja cristã africana. E aqui também há estratégias variadas que distanciam a compreensão dos circunceliões da problemática criada por Thompson. Uma delas é a de pensar o termo "circunceliões" (e sua contraparte "agonisticl”) como uma categoria abstrata para monges errantes violentos e fanáticos. Tal leitura se baseia na repetição de menções vagas a mártires suicidas ${ }^{12}$ e em evidências ambíguas de ascetismo errante nos textos de Agostinho, Ticônio e Isidoro de Sevilha, e também no significado da palavra "cella” no latim da África romana, que, além de "celeiro" e "taverna", pode significar ainda "altar dos mártires" (assim, os circunceliões seriam aqueles que ou circulam por celeiros ou por altares de mártires)..$^{13}$ A outra estratégia é a de enfatizar uma conexão orgânica entre circunceliões e donatistas, diminuir suas dissenções e interpretar os bispos donatistas e seu apoio à revolta de Gildo em 396 a 398 como uma versão africana dos potentados gauleses que controlariam as revoltas dos bagaudas. ${ }^{14}$

A organicidade entre donatistas e circunceliões é bem discutível. ${ }^{15} \mathrm{~A}$ visão de uma relação próxima entre os bispos donatistas e circunceliões parece muito mais um projeto de difamação que foi paulatinamente construído de Optato de Milevis (o primeiro a mencionálos) a Possídio (biógrafo de Agostinho), com Agostinho tendo desempenhado um papel central. Há indícios de algumas ações conjuntas, mas o que há de comum é muito mais uma mesma ideia de cristianismo que valoriza mais o martírio do que a unidade episcopal. As interpretações que propõem alguma organicidade entre donatistas e circunceliões têm grande dificuldade de explicar as sistemáticas recusas dos bispos donatistas em aceitar as acusações de Agostinho ou o apelo dos donatistas a autoridades seculares para lidar com os circunceliões, um apelo similar àquele que Optato e Agostinho demandam para aplacar a falta de segurança sobre a propriedade privada causada pelos circunceliões. $O$ que o projeto cecilianista de difamação dos donatistas tem de mais significativo para se entender os

\footnotetext{
${ }^{12}$ A questão dos esquadrões suicidas poderia ser explicada como expressão de desespero pós-repressão, como sugere Claude Lepelley (2001), mas me parece bem suspeito o caráter vago das descrições desses falsos martírios apresentadas pelos cecilianistas.

${ }^{13} \mathrm{O}$ primeiro a sugerir essa interpretação foi Frend (1951). Mas veja-se também a crítica demolidora dessa teoria por Brent Shaw (2011), que demonstra que Agostinho nunca usa cella com o sentido de altar, mas quase sempre com o de taverna.

${ }^{14}$ Para uma interpretação arraigada, cf. Brown (1961), Bustamante (2001), Caner (2002), Figuinha (2009), Frazão (1976), Pottier (2008) e Frend (1969).

${ }^{15}$ Para um estudo que se contrapõe a essa construção, cf. Kaufman (2009).
} 
circunceliões é que ele se sustenta na associação dos donatistas, adversários no controle da Igreja Cristã na África, a agentes rurais considerados desordeiros e violentos, ameaçadores da propriedade.

Contudo, quando as ações propriamente ditas dos circunceliões são descritas, o recurso utilizado é exatamente a já mencionada tópica: os circunceliões fazem mestres e escravos inverterem suas posições em carruagens e expulsam cobradores de dívidas das zonas rurais da Numídia:

\begin{abstract}
(...), então o outro Donato, (...) desejando pôr impedimento à unidade e obstáculo aos advindos, acima mencionados, ${ }^{16}$ enviou arautos pelos locais vizinhos e por todas as feiras, chamando pelo nome circuncelioes agonísticos (...) Pois quando, antes da unidade, esse tipo de homens estava vagando por diferentes lugares, e, quando Axido e Fasir eram chamados "generais dos santos" pelos mesmos homens insanos, ninguém estava seguro de suas posses. Naquele tempo, as cartas de débitos manuscritas perderam seu poder, nenhum credor teve direito de as executar; todos eram aterrorizados pelas cartas daqueles que se jactavam de serem os generais dos santos; e se alguém se demorava para contemporizar com as ordens deles [dos circunceliões], subitamente, uma multidão insana vinha correndo e os credores se protegiam do terror extremo daquele perigo, de forma que aqueles que mereciam exigir suas devidas prestações eram impelidos às preces humildes pelo medo da morte. Cada um deles se apressava em abandonar mesmo as dívidas mais altas e era reconhecido como um ganho escapar das injúrias daqueles. E mesmo as viagens mais bem vigiadas não podiam acontecer, porque os amos expulsos de seus veículos corriam servilmente à frente de seus escravos, que se sentavam no lugar de seus senhores. Por causa do julgamento e das ordens daqueles, a condição de mestre e de escravo era alterada (Optatus de Milevis, Contra Donatistas, 3.4).17
\end{abstract}

\footnotetext{
${ }^{16}$ Dois representantes dos cecilianistas acompanhados do exército imperial.

${ }^{17}$ tunc alter Donatus (...), inpedimentum unitati et obicem uenientibus supra memoratis obponere cupiens praecones per uicina loca et per omnes nundinas misit, circumcelliones agonisticos nuncupans, (...) nam cum huiusmodi hominum genus ante unitatem per loca singula uagarentur, cum Axido et Fasir ab ipsis insanientibus sanctorum duces appellarentur, nulli licuit securum esse in possessionibus suis; debitorum chirographa amiserant uires, nullus creditor illo tempore exigendi habuit libertatem, terrebantur omnes litteris eorum, qui se sanctorum duces fuisse iactabant, et si in obtemperando eorum iussionibus tardaretur, aduolabat subito multitudo insana et praecedente terrore creditores periculis uallabantur, ut qui pro praestitis suis rogari meruerant, metu mortis humiles inpellerentur in preces. festinabat unusquisque debita etiam maxima perdere et lucrum conputabatur euasisse ab eorum iniuriis, etiam itinera non poterant esse tutissima, quod domini de uehiculis suis excussi ante mancipia sua dominorum locis sedentia seruiliter cucurrerunt. Illorum iudicio et imperio inter dominos et seruos condicio mutabatur.
} 
Isso significa que, mesmo reconhecendo o componente religioso na ação dos circunceliões, ainda assim é necessário lidar com suas outras dimensões. E, do ponto de vista da classificação social dos próprios circunceliões, mesmo que se aceitasse a sua configuração como monges errantes, suas ações de enfrentamento de ricos e credores respondem a alguma demanda social dos pobres da zona rural da Numídia ou mesmo de outras regiões da África romana. Isto é, mesmo que os próprios circunceliões não fossem os camponeses insatisfeitos, a documentação demanda que se entenda as suas ações como respondendo à insatisfação dos trabalhadores rurais da Numídia. Além dos relatos das ações dos circunceliões, há outros indícios documentais dessa demanda, como uma parte da historiografia recente sobre a África da Antiguidade Tardia vem descortinando (Dossey, 2010; Shaw 2011).

\section{Conclusões}

É nesse contexto de mudança da historiografia que retomo a comparação entre circunceliões e bagaudas. Pois a combinação, característica dos circunceliões, de ações contra as hierarquias sociais no espaço rural com um cristianismo considerado rigorista me parece passível de aproximação da posição ideológica que fundamenta as críticas formuladas por Salviano de Marselha aos cristãos galo-romanos. Fazer uma investigação sobre essa possível proximidade significa observar a existência de diferentes respostas cristãs na África e na Gália romanas às relações de patronato na Antiguidade Tardia. De um lado, a perspectiva favorável ao patrocínio e à ordenação de cima para baixo da sociedade romana representada pelo cristianismo de filiação agostiniana (que opera tanto na visão histórica da sociedade quanto na teologia); uma perspectiva muito bem investigada e analisada por estudiosos modernos. Do outro, manifestações cristãs geralmente consideradas rigoristas que reconhecem as ações dos grupos subalternos como tendo uma lógica autônoma ou relativamente autônoma das ações das classes dominantes. A questão de fundo ainda não resolvida é a que tradição cristã ou a que demanda social essas manifestações respondem. Digo isso porque uma maneira comum com a qual parte da historiografia lida com Salviano é desmerecê-lo como um fenômeno ideológico isolado e excêntrico. Mas o que essa aproximação parece indicar é que não há nada de excêntrico nele.

Uma ponte possível entre Salviano e os circunceliões é um conjunto bem numeroso de sermões e textos cristãos, a maioria anônima, cuja datação é da Antiguidade Tardia, muitos do século V, e que podem ser originários da África, mas que foram conservados em quantidade substancial na Gália. Esses textos apresentam uma visão cristã da sociedade muito mais próxima da de Salviano do que da de Agostinho. Eu soube da existência desses textos apenas recentemente, por meio da investigação das condições de vida do campesinato africano feita por Leslie Dossey (2010). Isso não quer dizer que se deva assinalar imediatamente o cristianismo entre os motivadores ideológicos dessas insurgências, um fator bem claro no caso dos circunceliões, mas que parece bem distante das possíveis motivações das revoltas dos bagaudas. Dada a ubiquidade da produção ideológica cristã, existe nela espaço para contradições, dissenções e polissemia suficientes para que ela também reconheça as relações 
sociais da Antiguidade Tardia sob pontos de vista diversos dos da aristocracia e dos grandes proprietários.

Assim, quando se reconhece a tópica da inversão social como diferente daquela da bandidagem e a heterogeneidade dos discursos cristãos com relação aos de baixo, as evidências escritas tanto sobre bagaudas quanto sobre circunceliões parecem apontar não para um fortalecimento do patronato, mas para um enfraquecimento, ou uma crise efetiva dessas relações. Outras duas dimensões de análise, o debate sobre a natureza do colonato romano tardio e o que isso implica em termos dos estudos sobre o patronato nesse período também apontam nesse sentido. ${ }^{18} \mathrm{O}$ reconhecimento da existência dessas contradições e dissenções ideológicas me parece importantíssimo no que se refere aos estudos dessas duas insurgências, porque isso leva a revalorizar um elemento presente em Thompson e ausente na interpretação de seus críticos: a ideia de crise do controle patronal sobre os trabalhadores rurais.

Contudo, diferentemente de Thompson, é necessário ver o processo acumulado de desenvolvimento político e identitário desses grupos insurgentes não em termos de séculos, e sim de décadas. Além disso, também é necessário diminuir o peso da ideia de uma conspiração do silêncio, já que é possível ver na documentação um conceito mais preciso e circunscrito usado e aplicado para expressar o fenômeno das revoltas camponesas na Gália e na Hispânia, isto é, reconhecer que os autores de textos do século $\mathrm{V}$ sabiam muito bem que bagaudas queriam dizer revoltas de trabalhadores rurais. $\mathrm{O}$ mesmo vale para os circunceliões, pois o uso difamatório das suas ações feito pelos cecilianistas contra os donatistas só foi possível porque era possível reconhecer em suas ações o caráter de subversão social e de ameaça à ordem romana. Um caráter bem diferente no linguajar e nos efeitos sociais daquele que aparece no banditismo ubíquo no Império ou mesmo no martírio suicida que, aceitando-se as descrições agostinianas, era um problema circunscrito à África. Por fim, isso significa reconhecer nos levantes muito mais uma resposta política ao "tempo de agora" das condições sociais do trabalho rural na África dos séculos IV a V e na Gália do século III e V.

\section{REFERENCIAS}

AMMIEN MARCELLIN. Histoire. Texte établi, traduit et annoté par Marie-Anne Marié. Paris: Les Belles Lettres, 1984.

AUGUSTINE. Letters. Translation and notes by Roland J. Teske; editor, John E. Rotelle. 4 vol. New York: New City Press, 2001-2005.

AUGUSTINE. Sermons. Newly discovered sermons. Translation and notes Edmund Hill; editor John E. Rotelle. New York: New City Press, 1997.

\footnotetext{
${ }^{18}$ Sobre essas discussões, cf. as posições clássicas sobre o colonato e o aumento da patronagem: Jones (1958) e Ste. Croix (1998); as visões mais recentes que os relativizam: Wickham (2005), Dossey (2010) e Grey (2007). É importante também ter em mente a revolução causada pela arqueologia das regiões rurais tardo romanas (cf. Dyson, 2003; Wickham, 2005; Chavarría \& Lewit, 2004).
} 
AURELIUS VICTOR. Sextus Livre des Césars. Texte établi et traduit par Pierre Dufraigne. Paris: Belles Lettres, 1975.

BARTHOLOMEW, Philip. Fifth-Century Facts. Britannia. Vol 13, 1982, p. 261-270.

BROWN, Peter. Religious Dissent in the Later Roman Empire: the case of North Africa. History, v. XLVI, n. 1, p. 83-101, 1961.

BURGESS, Richard. The Gallic Chronicle of 452: A New Critical Edition with a Brief Introduction. In: Society and Culture in Late Antique Gaul: Revisiting the Sources. Mathissen \& Shanzer, 2001, p. 52-84.

BUSTAMANTE, Regina Maria da Cunha. Violência e “Terrorismo”: Circunceliões na África Romana. Boletim do CPA, Campinas, n.11, p. 121-146, 2001.

CANER, David. Wandering Begging Monks. Spiritual Authority and the Promotion of Monasticism in Late Antiquity. Berkeley: California University Press, 2002.

CHAVARRÍA, A., \& LEWIT, T. Archaeological research on late antiquity countryside: A bibliographical essay. In: W. Bowden, L. Lavan, \& C. A. R. Machado (eds.). Recent Research on the late antiquity Countryside. Leiden: Brill, 2004, p. 3-51.

DOSSEY, Leslie. Peasant and Empire in Christian North Africa. Berkeley: University of California Press, 2010.

DYSON, S. L. The Roman countryside. London: Duckworth, 2003.

EUTROPIUS. Abrégé de l'bistoire romaine. Traduction nouvelle avec introduction, notes, tables et index par Maurice Rat. Paris: Garnier Frères, 1934.

FIGUINHA, Matheus Coutinho. Servos de Deus. Monasticismo, Poder e Ortodoxia em Santo Agostinho. São Paulo: Annablume, 2009.

FRAZÃO, Elza Rossi de Aguiar. Donatismo e os circunceliões na obra de Santo Agostinho. São Paulo: FFLCH-USP, 1976.

FREND. W. H. C. The Donatist Church. Oxford: Oxford University Press, 1951.

FREND. W. H. C. Circumcellions and monks. Journal of Theological Studies, New Series, v. 20, n. 2, p. 542-549, 1969.

GREY, Cam. Contextualizing Colonatus: The Origo of the Late Roman Empire. Journal of Roman Studies, n. 97, p. 155-175, 2007.

JONES, A. H. M. The roman Colonate. Past \& Present, n. 13, p. 1-13, 1958.

KAUFMAN, Peter Iver. Donatism Revisited: Moderates and Militants in Late Antique North Africa. Journal of Late Antiquity, v. 2, n. 1, p. 131-142, 2009. 
LEPELLEY, Claude. Iuvenes et circoncellions: les deniers sacrifices humains de l'Afrique antique. In: Aspects de l'Afrique Romaine. Les Cités. La Vie Rurale, Le Christianisme. Bari: Edipuglia, 2001.

MINOR, Clifford E. Bagaudae or Bacaudae? Traditio, n. 31, 1975, p. 318-322.

MINOR, Clifford E. Bacaudae: a Reconsideration. Traditio, n. 51, 1996, p. 297-307.

OPTATUS. Against the Donatists. Translated and edited by Mark Edward. Liverpool: Liverpool University, 1997.

PANEGYRICI LATINI. Panégyriques latin. Texte établi et traduit par Édouard Galletier. Paris: Belles Lettres, 1949.

POTTIER, Bruno. Les Circoncelions. Un mouvement ascétique itinérant dans l'Afrique du Nord des IVe et Ve Siècles. Antiquités africaines, v. 44, n. 1, p. 43-107, 2008.

QUEROLUS. Comédie latine anonyme. Le Grincheux (comédie de la petite marmite). Texte établi et traduit par Catherine Jacquemard. Paris: Les Belles Lettres, 1994.

RUBIN, Zeev. Mass Movements in Late Antiquity - Appearances and Reality. In: Malkin, I \& Rubinsoh, Z.W. (org.) Leaders and Masses in the Roman World. Leiden: Brill, 1995, p. 129-187.

RUTILIUS NAMATIANUS. Sur son retour. Texte établi et traduit par J. Vessereau et F. Préchac. Paris: Les Belles Lettres, 1933.

SALVIEN DE MARSEILLE. Owres II. Du gouvernment de Dieu. Trad. Georges Lagarrigue. Paris: Editions du Cerf, 1975.

SANZ BONEL, Victor M. \& Lázaro Garcia, Gonzalo. La problemática Bagauda (Siglo V d.C.) en el Valle del Ebro: Reflexión Historiográfica. In: VV AA. Homenaje a Antonio Durán Gudiol, Huesca, 1995, p. 741-761.

SANZ BONEL, Victor M. La aportación pagana, Querolus y Rutilio Namauniano, al carácter cristiano de los bagaudas. Aragón en la Edad Media. Estudios de economía y sociedad, n. 16, p. 1471 1486, 2000.

SHAW, B. D. Sacred Violence. African Christians and Sectarian Hatred in the Age of Augustine. Cambridge: Cambridge University Press, 2011.

SIDOINE APOLLINAIRE. Poèmes. Texte établi et traduit par A. Loyen. Paris: Les Belles Lettres, 1960.

STE. CROIX, G.E.M. de. The class struggle in the Ancient Greek world. Ithaca: Cornell University Press, 1998.

THOMPSON, E. A. Peasant revolts in Late Roman Gaul and Spain. Past \& Present, n. 2, p. 11-23, Nov. 1952. 
TILLEY, Maureen (org.). Donatist Martyr Stories. The Church in Conflict in Roman North Africa. Liverpool: Liverpool University Press, 1996.

TILLEY, M. The Bible in Christian North Africa. The Donatist World. Minneapolis: Fortress, 1997. VAN DAM, R. Leadership and Community in Late Antique Gaul. Berkeley: University of California Press, 1985.

VERSNELL, H. S. Inconsistencies in Greek and roman Religion 2. Transition and Reversal in Myth \& Ritual. Leiden: Brill, 1994.

WHITTAKER, C. R. Rural labour in Three Roman Provinces. In: Land, City and Trade in the Roman Empire. Aldershot: Variorum, 1993 [1980], II, p. 73-99.

WHITTAKER, C. R. Landlords and warlords. In: Rich, John; Shipley, Graham (eds.). War and Society in the Roman World. London: Routledge, 1995, p. 277-302.

WICKHAM, Chris. Framing the Early Middle Ages. Europe and the Mediterranean, 400-800. Oxford: Oxford University Press, 2005.

WOOD, Neal. Populares and Circunceliones: the Vocabulary of 'Fallen Man' in Cicero and St. Augustine. History of Poltical Thought, v. VII, n. 1, p. 33-51, 1986.

ZOSIME. Histoire nouvelle. Texte établi et traduit par François Paschoud. Paris: Les Belles Lettres, 1989.

Recebido em: 6 de abril de 2016 Aprovado em: 25 de janeiro de 2017 